\title{
Disability as Socio-Political and Biomedical Construct: A Passionate and Pensive Reappraisal of a Global Phenomenon
}

\author{
Michael Onyedika Nwalutu \\ University of Toronto, Toronto, Ontario, Canada \\ Email: nwalutu@yahoo.co.uk
}

How to cite this paper: Nwalutu, M. O. (2019). Disability as Socio-Political and Biomedical Construct: A Passionate and Pensive Reappraisal of a Global Phenomenon. Sociology Mind, 9, 258-272. https://doi.org/10.4236/sm.2019.94017

Received: August 12, 2019

Accepted: September 26, 2019

Published: September 29, 2019

Copyright ( 2019 by author(s) and Scientific Research Publishing Inc. This work is licensed under the Creative Commons Attribution International License (CC BY 4.0).

http://creativecommons.org/licenses/by/4.0/

Open Access

\begin{abstract}
This paper uses personal tragedy theory and social model to interrogate two contextual narratives depicting how disability manifests and is made to manifest in labeled bodies. In the analysis, disability discourses provide a lens through which to understand how disability is done in everyday life, and in different socio-cultural contexts. It reveals how bodies are made to disappear and dys/appear when confronted with social normative constructs of the dominant class. Domba's transplanted kidney, as well as the bodies of the segregated students enlisted to Room two zero two of an Ontario school remains both sites of oppressive subjectivity, spaces of contradictions and negotiations at which we learn how bodies relate with the world, and following this relationships the bodies are changed, providing means for these bodies to speak back to the world. Coming to terms with this theorizing helps us to visualize Domba's body and those of the students living with learning disabilities as sites of political and socio-cultural struggle aimed at establishing supremacy and dominance, and as a corporeal reality in which bodies and commodified body parts simultaneously represent symbols of subjective hegemony of the dominant social class, and a platform for interrogation, negotiation and assimilation between the two social structures.
\end{abstract}

\section{Keywords}

Transplant, Disability, Organ, Construct, Learning, Policies, Transmigrated, Bodies, Deviant

\section{Introduction}

In this paper, I will be theorizing disability as both a subjectively socio-political experience and a space of doing. I will be cross-examining the appearances of 
disability through the lenses of different cultural assumptions; while reviewing the manifestations of cultural assumptions through the metaphors of disability. Using two narratives and existing scholarly discourses, this paper seeks to analyze and synthesize information that would delineate two critical perspectives for understanding disability - that of discovering how disability is constructed and perpetuated as an oppressive tool of the social dominant class in different socio-cultural environments-and disability as a site of consciousness, contradictions and negotiation, a space of doing that reveals how bodies respond when confronted with oppressive paradigms of the dominant social class. I must add here that an appraisal of disability as a sign of strained relationship with community is critical for our understanding of how strained communal relationship foregrounds the constructs of disability. While drawing narratives from two socio-cultural settings spanning North through South America, this study deliberately aims to reflect not just the omnipresence of disability as a concept, but the diverse ways it is made to manifest in different socio-cultural environments. The first narrative will investigate disability in a special education program of a junior/middle school as a way of understanding how disability manifests itself and is being manifested through segregated classroom practices of a typical Canadian classroom. The paper will attempt to address such questions as: how does disability manifest itself and is being rendered visibly in academic environments? Is stigmatized and racialized body synonymous with disabled body? How does the exclusion of disabled bodies reconstruct and reproduce disability as the site of oppression and contradictions? Providing answers to these questions would position us to well appreciate the polyvalent swings of disability as a socio-political concept.

The second narrative will be taken from Benedicte Ingstad's and Susan Reynolds Whyte's text, DISABILITY IN LOCAL AND GLOBAL WORLDS. It is about the ordeal and cultural dilemma of Domba, a 41-year-old Suya man from the traditional Indian society of Brazil. His experience is critical to the understanding of representations of disability as a sign of strain in communal relationship and refractions of social practices informed by perspectival shifts in the way disability are experienced and perpetuated. This narrative helps us to explore disabled body as a site of oppression and negotiation, which goes to confirm the view that how we relate with the world change our experiences and our bodies, providing means for us to speak back to the world. The bio-politicization of the bodies of people living with disabilities expressed in the medical policies of the Brazilian Sao Paolo Hospital and the Ontario school system depicts a lopsided power relationship between the social dominant groups and the marginalized bodies; the bodies of Domba, a member of the Suya Indigenous community in Brazil, and those of children diagnosed with learning dysfunctions in Ontario Canada, which became both sites of conflict and location of resistance between the interests of the dominant group and its "abnormal" subjects. These "deviant" bodies continue to experience hegemonic imposition of the dominant group's 
policies and practices, suggesting that the perpetuators of the old hierarchies and inequalities are basking in the falsity that the social relations were currently voluntarily accepted by all members of the society. In a reference made of passage into law of the Accessible Canada Act, Bill C-81 for instance, Heff Matthews states that in the Bill yet to become an Act of Canadian Parliament, the federal government established measures that would bring the country into observance of the commitments that it made when it endorsed the Convention on the Rights of Persons with Disabilities (CRPD) in 2010, it meant that nine years later in 2019 Canada was yet to make right their promise (see: Matthews, 2019). Also in a representation using hearing loss as an example, Brianne Lott (2017) reasons that it is actually the society's reliance on sounds and lack of inclusion that puts people living with hearing impairment at a disadvantage in certain situations. In other words many of the individuals with hearing impairment do not see their loss of hearing as disability but the society in which they live does. Arguing for the benefits of inclusivity Lott states that common design is actually helpful not just for people with impairment but for everyone. Just as using different modes of communication in training, workshops and conferences are beneficial for all participants, whether they are "normal" or persons with disabilities, but also those who simply learn in different forms; so is cutting out curb on pedestrian lane beneficial to people with wheelchairs and walkers as well as parents with infant-strollers. (see also: Julie, 2019). I will be attempting answers to the questions: how is disabled body viewed as different from "normal"? How is disability done differently in different societies? How does reducing disability to disadvantage cause the disabled bodies to disappear and dysappear? How does commodified body part represent disability in the transmigrated body?

\section{Disability and the Politics of Classroom Segregation: A Canadian Public School Experience}

The room "two hundred and two" of a junior/middle school in review had sixteen regular students, nine of which were girls and seven, boys. Three other students who newly immigrated into Canada often joined the class from their regular rooms. It was a Special Education Home Room, and English as a Second Language (ESL) class structured for remediation of students diagnosed with learning disabilities. My assignment as a student teacher in this classroom had its daily dose of challenges that bordered around managing the students' attitudinal issues, including lack of concentration, distraction of other students, hyperactivity, loss of self-esteem, and other detrimental dispositions, such as talking down on self and peers, cursing or swearing at the teacher, passing ribald comment during lessons or talking ill of others. Since these were part of why the school and medical authorities diagnosed them with "abnormalities", disability is here represented by the school and education authorities as psycho-social maladjustment. These and low academic achievements are some of the unenviable qualities not found among the so called "high achieving" or "fast learning stu- 
dents", the "able" or the "normates". The tag of low academic achievement also explains why this group of kids was classified as "learning disabled". Here again, disability is represented as loss of physical, academic or social skills. The students in room two zero two, because of lack of concentration and disorderly conducts consistently found themselves performing below the benchmarks in almost all their subjects. For instance, a systematic review of series of classroom tests in major subjects revealed that while the "normal" students in the regular classrooms scored far above the average, many of those diagnosed with learning disabilities struggle to hit the average marks in reading, spelling, written expression, mathematics computation and problem solving. Disability is here represented as inability to reach the benchmark score in academic tests. The students were considered lacking in academic and social skills because reckoning with their ages and levels of intelligent quotient (IQ), psychologist, and medical professionals believe that they were unexpectedly underachieving by the "normal" academic standards.

In the incipience of its intervention efforts in 1999, the World Health Organization, Ontario Education Ministry and the Learning Disability Association of Ontario (LDAO) agreed in their definitions that learning disabilities, a neuropsychological or neurobiological impairment is a "disorder", outside the "normal" range or continuum of human function in terms of an individual's ability to process information and communicate ${ }^{1}$. According to the 2001 publication of LDAO, this disorder is usually described as lack or loss of normal function. Of great import to us in this document is the indication that within the educational systems in the province, learning disabilities are included among "communication exceptionalities", and in lay terms described as "problems" with information processing. These outstanding institutions advocated for early intervention to restore "order" in the "disorder", prominent among which is the LDAO's Promoting Early Intervention for Learning Disabilities (PEI) (disability is here, socially represented as a disorder). Since they were individually reckoned with peculiar disabilities, the students were subjected to different in-class diagnostic tests and meetings with the Identification, Placement and Review Committee (IPRC). This group which comprised of teachers who had special education training was headed by the school principal. Their assignment is the identification which centered on NEED or "problem", (disability is seen as problem to be solved - need) and this group makes recommendations for the students to meet with the liaison education Psychologists who have the responsibility under the Regulated Health Professions Act and Section 1 of the province's Education Act, to trace the CAUSE or the diagnosis (again disability is represented as biomedical case) and make recommendations for interventions, rehabilitations and remediation involving the use of the individual education plans (IEPs) and withdrawal to the homeroom program from their regular classrooms. This arrange-

${ }^{1}$ Operationalizing the New definition of Learning Disabilities for Utilization within Ontario's Educational System, Learning Disabilities Association of Ontario, 2001. 
ment favored the notion that students with learning disabilities constitute a disruption of the orderly flow of learning in the regular classroom. They are perceived as problem that would be shunted out of the way of normal process to be fixed. Anita Silvers in her Fatal Attraction to Normalizing: Treating Disabilities as Deviations from "Species-Typical" Functioning reasons that, simply avoiding or excluding those who fall away from the common standard is the usual concomitant of our passion for congregating with those who most resemble us ${ }^{2}$. The students complained that being in room two zero two meant that they were "written off", and their peers in the regular classrooms from where they were extracted often taunted them with the phrase, "retards class". It was observed however that whenever they had lessons in regular classrooms with their colleagues who were regarded as; "normal students", "learning at fast pace", "well behaved", "intelligent", "respectful and responsible", students from room two zero two worked and related well with their peers, and were more submissive to their teachers.

While the academic and medical authorities have represented the educational and social life of this group of students as failure to achieve expected standards; their peers, represented disability as "despicable" and "object of ridicule". Curious to find out the reason for the changes in the room two zero two students' behavior and learning pattern, this paper realized in an inquiry that the students were detached from their classes, leaving their friends, peers and informal groups to the new gathering of those classified as "at risk" (disability is represented here as helpless and weak-they must be helped if they would achieve anything in life (at risk of failure). The students felt frustrated because they were labeled and their friends in the regular class knew them now as retards, at risks, or burdensome students, they therefore tried as much to "act it out". Note that labels of ridicule are mostly transitional, so the students saw their future already defined by the authorities concerned. In other words, if whatever went wrong with their studies-familial, financial, physiological, or emotional-gets strengthened out and things change tomorrow for good, they will still be seen in the light of this label and categorization by their peers whom they are bound to meet at various social of political strata in the future. Bearing in mind that most of these students were from poor families, another question arises, which was that of marginalization. Were all familial and environmental factors taken into consideration in the process of analyzing the student's performance and response to instructions? This question becomes necessary in view of the fact that the newly immigrated students in this classroom were obviously struggling to fit into the system of education in their new environment. Their parents like every other working-class parent may have been engaged in menial jobs all day long to keep up with the bills that they have little or no time at all to guide

${ }^{2}$ Silvers, Anita, Fatal Attraction to Normalizing: Treating Disabilities as Deviations from "Species-Typical" Functioning in Parens, E. (Ed) 1998, ENHANCING HUMAN TRAITS: ETHICAL AND SOCIAL IMPLICATIONS. Washington, Georgetown University Press, Pg 104. 
and direct their wards' academic works at home. Additionally, some of the students are raised by single parents, which made their matters worst. If they were therefore sidetracked into home room program without taking into account their various barriers, it is another representation of disability, because they were seen as "social burden" that disrupts the smooth flow of academic activity for those students from wealthy and stable homes. At this juncture, one would be tempted to ask; would these students be secluded and labeled in the homeroom if they were of rich or "normal" parentage?

\section{Domba's Kidney Transplant: The Notions and Practices of Disability in Suya Community and Sao Paulo Metropolis of Brazil}

The second manifestation of disability is the incident in the life of a 41-year-old man, Domba from Suya, (a Mexico Indian Indigenous society), who was diagnosed with genetically terminal renal disease for which kidney transplant was prescribed by the chief medical officer of the Brazilian Medical Center in Sao Paulo, Brazil. The ethnographic dilemma of Domba in this incident brought to light the concepts of social construction and propagation of knowledge as well as society's propensity to pommel the deviant "other" to conform to her stipulations of the "normal". Domba, his father, in-law and all his kin would never imagine Domba cut open and his kidney (or any part of his body which is indivisibly tied to his spirit-soul) replaced, worst still with a kidney of "accidented Whiteman". To all of them it meant Domba died. Disability is therefore represented in both Domba's ailing body and the body part he was to receive as "loss" and "strange" respectively. After their own shamanic medications failed, and his health continued to deteriorate to the point he could no longer perform his expected social functions-hunting, farming and fishing to sustain his family-Domba accepted the prescription to be treated with the Whiteman's medicine and received the approval of his father, wife and the rest of his kin.

Domba's kin used the Shamanic medication because their own traditional society as in most other Indigenous communities, viewed any man who is not able to engage daily in economic activities for the upkeep of his family as disabled. Disability is thus represented as dysfunction or "loss of function" and therefore he became a deviant and out of "normal". So the community must medically restore his loss of physical functions to have him back to normal. A normal Suyan must not only be active in all the economic activities in the village: hunting, fishing, farming, house construction and implements manufacturing; but must be exemplary in the social participations which includes, family upkeep, attending to the needs of the kin, participating in warfare, social gatherings and bringing in supplies to the members of the society who are no more active because of age. Domba was part of these functions until his health began to wane. Domba's father, Romdo was the traditional head and head Shaman in his village, so every hand was on deck to see him recover to regain his physiological functions. Domba's 
reputation as the son of a traditional head of a social group brings us to another manifestation of disability. When he arrived at the Sao Paulo hospital for treatment, the chief surgeon picked special interest in his case not just because, according to him, it was the first transplant of an Indian from province, but also because of his status and his family background (emphasis, mine). Dr. Medina admitted that he gave far more attention to Domba, as a "wild", culturally active Indian than he gave to "ordinary" patients (emphasis mine). If they were ordinary, they had no status like Domba, so they are "deviants" and only needed second class treatment. Disability is represented here as low social status. Dr. Medina went as far as skipping many other patients who were on the waiting list for kidney before Domba and gave him not just the priority, but a "very good kidney". In an interview, he reasoned, the Brazilian Indians have suffered so much. Romdo highlighted a remarkable shift to the cultural constructs and representations of disability. He reasoned that his son's sickness resulted from his (Domba's) refusal to pierce his lip and to wear a lip disk, a traditional Suya ritual, apparently with protective potentials. Hence he represented disability differently, as a "strain in community relationships". Dr. Medina's defense which is similar to Romdo's claim was in line with the personal tragedy theory which locates problem in the body and views disabled person as weak and needing help. The medical phenomenon of organ transplant raises the awareness of most of Suya cosmology and practices which were at variance with, and therefore non-conforming to the western medical practices. They operated in two different socio-cultural settings that are anchored on divergent normative values and standards, which call for a critical review of the manifest suppression of difference as it affects disparate forms of biosociality. The Suya people would as soon at birth eliminate a child born with visible deformity (disabilities-represented as unwanted visible physical deformity in Suya traditional society), but what happened to Domba was internal and invisible, and developed gradually as he grew into maturity. We are also faced here with critical issues for understanding disabilities among the Suya. First of all, we realize the double consciousness of human person. Domba's body had a disease (disability located in the body, corporeal being), not him (his soul or spirit) for which his kin and community knew him.

Therefore there was a physical or biomedical shift from the Suya understanding of human person as an integral indivisible bundle of two co-existing matters (spirit and body). In other words, Domba's receiving a kidney from a Whiteman meant that his part, and as a result his original person was gone (dead). Suya cosmology insists that Domba's transplant still left him disabled. Disability is represented as "dead body, or impotent corporeal persona", and a new Whiteman would live in his body. His wife complained that she would prefer to be sleeping with a disabled body of the original Domba, than sleep with the new Whiteman husband, (disability is represented as contaminated body) symbolized by the commodified body part. Nancy S. Hughes and Mariana L. Ferreira 
reasoned that there was a conflating normative here bordering on the introduction of seemingly alien conceptions of the body, corpse, cadaver and its parts; integral versus indivisible bodies and new definitions of person ${ }^{3}$. Domba must not only meet the standards of normality in his Suya traditional community but that which would make him acceptable to and seen as "normal" by the metropolitan Brazilian society in which he worked. The two incidents narrated above were sure cases of how disability is done albeit, in two different environments and three distinct societies.

\section{Understanding Disability in the Suya Brazilian Community and Sao Paulo Metropolis: Domba's Story}

The statement of the chief surgeon of the Hospital Sao Paulo, Dr. Medina, "Our [Brazilian] Indians have suffered so much, I did my best to make sure that Domba got as quickly as possible to the head of the waiting list and that he got a very good kidney" ${ }^{\prime}$, would serve as a good launching-pad for anchoring discourses on the constructions and intersections of disability as well as the perpetuations of oppressive subjectivity as revealed in the social interactions and the subversive eclipsing of the traditional cultural heritages of the Brazil Indians by the oppressive stranglehold of the dominant Brazilian metropolitan society. It is quite in order to begin by asserting that Domba's corporeal essence became the center of interactions, contradictions and confluence to the forces of the two hegemonic societies. Each insists on transforming and recovering Domba's transgressed "unruly" body to fit their respective constructions of a "normal" body, and by so doing, they left his disabled body in a pitch of cultural dilemma. And by virtue of being a "subject" of the two dominant cultural forces: the metropolitan Brazilian socio-cultural environment where he worked and lived-represented by the biomedical interventions of the professionals of the Hospital Sao Paulo and Domba's Suya cultural community-represented by the shamanic interventions, his body became a space of exertion of influence for these inevitable choices. Dr. Medina's statement could be interpreted in the light of the personal tragedy model of disability studies which resonates with the biomedical model. In personal tragedy theory disability is conceived as a "problem" and is located in the disabled body. The biomedical model ascribed the problem to the functional limitations or psychological losses in the body. The medical model is characterized by professional dominance, expertise medicalization, and individual treatment. It is the personal tragedy theory of disability that paved the way for the "normal" people to see disabled people as weak and helpless. This invokes sympathy rather than empathy and is the direct opposite of the social model which locates the "disabling problem" in the society. Michael Oliver, arguing for the social model reasons that it is all the things that impose restrictions

${ }^{3}$ Nancy S. Hughes and Mariana L. Ferreira in Ingstad, B. and Whyte, S.R., 2007, Disability in Local and Global Worlds, University of California, Press, LA, USA. P. 170-2.

${ }^{4}$ Ingstad, B. and Whyte, S.R., 2007, Disability in Local and Global Worlds, University of California, Press, LA, USA. P. 170-2. 
on disabled people; ranging from individual prejudice to institutional discrimination, from inaccessible public buildings to unusable transport systems, from segregated education to excluding work arrangements. He asserts that the consequences of this failure do not simply and randomly fall on individuals but systematically upon disabled people as a group who experienced this failure as discrimination institutionalized throughout society ${ }^{5}$.

Domba's body therefore, became the personification of a segregated, minoritized and racialized community of "suffering", "disabled Indians", who need help. The contradictions of the oppressive subjectivity Domba encountered during his kidney transplant also brought to light the contradictions of the social construction of knowledge in which his body was made to both "disappear" and "dysappear" when it was confronted by the standards set by the two socio-cultural environments he traversed. If according to Anita Silvers medicine views bodily parts and organs, individual human bodies and people from a functional perspective ${ }^{6}$, then the loss of function left Domba at the mercy of medicine if he would ever regain his identity within Brazilian metropolis where he was working as a janitor. But decision over kidney transplant was not a unilateral one. His father, other shamans in the community and his kin would share in his transmigrated body as they were partakers of its marginalization, and subsequent transgression. (Suya cosmology establishes collective ownership of the body). When Domba accepted the offer of a strange Whiteman's kidney, he (and his entire substance group) accepted into themselves a new social and psychological persona. They all became "part white". This helps one understand why Domba's complain that red pepper raises the risk of painful urination in his new kidney meant all members of his substance group stopped eating red pepper as they are now partakers of Domba's corporeal essence. These ordeals, as part of a collection of Domba's Suya construct were suppressed as "disabled" and made invisible by the illusions of normalcy and wholeness inherent in the practices of the Hospital Sao Paulo professionals. "The transplant surgeons did not then, and still do not today, understand the severity of Domba's dilemma, and they repeat to Domba and his wife like mantra the biomedical platitude that, "it makes no difference whose kidney you have"8. Erevelles implies that the putative positions of "wholeness" or "normalcy" ascribed to the practices of the dominant class, such as those exhibited by the professionals of the Hospital Sao Paulo (personal interpolation) is in itself illusory and becomes vividly apparent when one examines how the construction of the normative self is in fact predicated on the existence of the disabled "Other".

Domba also lost his janitorial job in Sao Paulo, Brazil due to loss of physical functions and was as well deemed not worthy to continue in his Suya communi-

${ }^{5}$ Oliver Michael.1990, p.33.

${ }^{6}$ Anita Silvers, 1998, Ibid p 97-119.

${ }^{7}$ Ingstad, B. and Whyte, S.R., 2007, Ibid. p. 172.

${ }^{8}$ Ingstad, B. and Whyte, S.R., 2007, Ibid. p. 172

${ }^{9}$ Erevelles, Nirmala. (2000). "Educating Unruly Bodies: Critical Pedagogy, Disability Studies, and The Politics of Schooling". Educational Theory, Vol. 50 (1): 25-47. 
ty's economic activities. As far as the two socio-cultural environments were concerned, Domba's body was a "deviant" that needed to be transformed, rehabilitated and restored. His Suya community, to whom the body and spirit are integral indivisible whole, resorted to shamanic practices to achieve this goal while the Hospital Sao Paulo professionals prescribed and carried out kidney transplant surgery as a way of achieving same goal. If we decontextualize Domba's relationship with these contradictory social forces exerting influence on his disabled body, we would be having a body whose experiences have been altered by the world and which now gives it means for speaking back to the world. In the view of Paterson and Hughes, one can argue that the disablist and disabling socio-spatial environment produces a vivid, but unwanted consciousness of one's impaired body. Here the body undergoes a mode of "dys/appearance" which is not biological but social ${ }^{10}$. Domba's ailing body was thus a constant reminder of unwelcome reality to both his Suya society and the Sao Paulo metropolis in which he suffered the loss of socio-economic functions as well. This featured remarkably in their exerted struggles for dominance on his body which resulted in his confinement in the hospital throughout the recuperating period. Paterson and Hughes acknowledged that "the disability studies movement has successfully politicized the social and spatial environment". In other words disability studies have drawn attention to the ways in which dominant norms and practices work, on the one hand, to exclude people with impairments from the mainstream of contemporary society, while on the other, confine them to special areas and venues ${ }^{11}$.

While Domba's disabled body remained a site of contradiction and space of influence for the two dominant cultures struggling to establish hegemonic control through transformative processes, Santiago Solis warned that attention be focused on the experiences of disabled people rather than on the imposition of normalizing, medically-based values. This hardly was the case with Domba. In an interview he granted two anthropologists as he was recovering in the Hospital Sao Paulo, the subversive nature of biomedical practice and the repressive professional spirit of the dominant culture led Dr. Medina to severally interject Domba's phenomenological narration of his experiences with western medical dictums meant to render "invisible", as "abnormal", "ridiculous" and therefore unfounded Domba's Indian interpretations of his ordeal. But while Dr. Medina admired Domba's strength of character, the surgeon could not resist correcting the Indian from time to time in the midst of Domba's narratives. When, for example, Domba spoke of seeing shamanic birds in the operating room, Medina chuckled and said dismissively, "well, yes, but that was just a predictable effect of the anesthesia". Or when Domba referred to the magically protective salve that his wife put on his abdomen just before the surgery, Medina said, "Oh, but our nurses would have washed that off, as we have to maintain a sterile field"12. I

${ }^{10}$ Paterson \& Hughes, 1999: p. 603.

${ }^{11}$ Ibid. 597-598.

${ }^{12}$ Ingstad, B. and Whyte, S.R., 2007, Ibid p. 173. 
would like to invoke for the last time, Nirmala Erevelles's view on critical race theory and disability studies, which she argues originated from same foundational springboard while allowing unique focal lenses through which to understand social relations. Erevelles reasons that both CRT and DS foreground the assumption that race and disability are socially constructed. Citing Haney Lopez and Thomson (1997), and in line with Santiago Solis (2006), Erevelles alleges that race is a product of human rather than abstract forces while disability is the attribution of corporeal deviance-not so much a property of bodies-but rather a product of cultural rules about what bodies should be or $\mathrm{do}^{13}$.

\section{Theorizing Disability in Everyday Life: Discourses and Reflections on the Narratives}

The thematic relevance of this paper is in two folds: first, the influence of the power of colonization (imposition of hegemony or socio-cultural domination) on bodies living with disability depicted in the control and manipulation of their body parts and functions by the educational and medical professionals and the society. The colonization or imposition of dominance finds expression in the prescriptions meted out to both the students with learning disabilities in an Ontario school system; and Domba's (a Brazilian of Suya Indigenous extraction) ailing biomedical ordeal. Both narratives are quite consistent with Michael Oliver's individual model of disability that comprised the personal tragedy theory (which coins and locates a problem in the body); the psychological or professional theory (which assumes authority over normative knowledge) and the medicalization theory which sets out to recover or rehabilitate the "ailing" or dysfunctional body. Second to this theme is the subjects manifest resistance to the imposition of hegemonic power by the social dominant group. These were depicted clearly in the students manifestation of different attitudes while studying in main-stream classes with their peers as opposed to their mien when confined in room two zero two; and instances where Domba and his kin would engage their shamanic and cultural beliefs and practices in opposition to whatever the Western medical professionals in the Sao Paulo Hospital prescribed to resolve his renal problem. The two parallel narratives explore the level of hegemonic impositions on bodies of people living with disabilities; and by disturbing the normative assumptions of the oppressive social systems; the article situates disabilities as metaphors of cultural domination, oppression and resistance. Throughout the article, lines of comparison are drawn depicting notions of "normal" as upheld by the social dominant group, which are in opposition to the belief systems of the subjects, in these cases: the Suya Indigenous beliefs and practices; as well as the epistemic saliency (lived experiences) of children diagnosed with learning disabilities that were segregated from the mainstream classrooms. In these instances culturally induced biases and contradictions (Western health/Academic versus Suya Indigenous worldviews) pervade the narratives of

\footnotetext{
${ }^{13}$ Erevelles p. 274.
} 
the article. Children diagnosed with learning disabilities as well as Domba became metaphors of a disease, deviation and resistance. Their bodies were both sites of resistance and protected space of struggle between opposing normative, a figurative house where in mingled two contradictory worldviews. These bodies became symbols of disability by the bio-medical prescriptions and the deviant body must seek normative.

The social practices in which class, race, gender and sexuality as constructs for establishing, and perpetuating students' subjectivity in academic environments are currently in focal view of scholars. The poststructuralists' shift in critical pedagogue has sought to recover the importance of the body as the site of political and cultural activity in educational contexts ${ }^{14}$. Henry Giroux therefore advocated for a critical border pedagogy that foregrounds the practices supporting the body/subject as the site of cultural struggles over social forms such as language, ideologies, significations and narratives in order to create borderlands in which diverse cultural resources allow for the fashioning of new identities within existing historical practices. The current practices according to Giroux, consistently promote the marginalization of disability and related issues by running two education systems for the disable students and the normal students. The categories listed above are enough evidence that American public educational system deliberately excluded "disabled body" in the construct that theorists advocated. In other words, the poststructural theorists' slogan of united to empower the powerless and to transform social inequalities and injustices could at best be interpreted as disabling the disabled body, as it is essentially tantamount to running with the hare and chasing with the hound.

As depicted in the first narrative, students in the room two zero two were labeled, categorized and stigmatized by the policies and structures put in place by the dominant class represented by the education authorities. Through their subjective policies, and in line with the dictum of social construction of knowledge, standards of academic achievement, social and adaptive skills were embedded in oppressive systems and structures developed and perpetuated to trail disabled students through life-in academic institutions, job employment, access to public institutions-and meaningful participation in other socio-political activities. Their peers in the school recognized their separation, and subsequently taunted them for being different (because being disabled also means having a stigmatized body, an embodiment of unwelcome consciousness, different from the "other"). The disabled students who got secluded into special education homeroom were by this practice made to disappear (become invisible) from the "disruption" they constitute to the mainstream academic environment; and dys-appear as unruly bodies to their colleagues. This means they appeared as abnormal and despicable to their peers, the "normal students". ${ }^{15}$ The marginalization is sustained and updated in the Education Ministry's databank and policy documents which consis${ }^{14}$ Erevelles, Nirmala.

${ }^{15}$ Clare (2001). “Stolen Bodies, Reclaimed Bodies: Disability and Queerness", in Public Culture. 13(3): 359-365. p.605. 
tently maintain unfavorable reports that trails them through the ladder and eventually renders a large number of them unemployable in the unforgiving competitive capitalist system that nurtures the disequilibrium. Considering that it was the system that categorized the students in the narrative, the standards which determine the bodies to be branded "abnormal" and the "other" would be said to be pre-designed to achieve that goal, and regulated to systematically occlude students who were largely of poor parentage and from newly immigrated families. The impoverished and racialized bodies thus, become synonymous with disabled bodies at the point successful erasure of this group of students from the mainstream was achieved. Nirmala Erevelles believes that although the poststructural argument that posits a critical pressure on foundational and normative constructions of reality may appear plausible to disability studies, it ignores the harsh reality of disabled people's lives, which are bounded by oppressive social and economic conditions that are much more difficult to transcend ${ }^{16}$. Bowles and Gintis cited in Erevelles argue that schools are ideological state apparatuses that rather than attempting to meet the needs of the citizens, devise administrative curricular, and pedagogical practices that reproduce subject positions which sustain exploitative class hierarchies. According to Bowles and Gintis, educational institutions legitimated the distribution of wealth, privilege and status in capitalist societies through the administration of tests that claim to measure intelligence, which is a presumed genetic attribute that supported the ideology that the poor are poor because they are stupid. As a result the poor working class is subjected to accept individual responsibility for the condition of poverty and segregation that continue to prevent them from adequately meeting their fundamental needs.

The idea of holding the poor accountable for their failures is a clear reverberation of the biomedical and personal tragedy theory of disability studies which locates disability in the body of the disabled rather than the failures of the society ${ }^{17}$. Here, the political import of subjective experiences remains that as the racialized and stigmatized bodies internalize the social loss they suffer from the dominant class through its established structures of exclusion, they strive to forge or reclaim their identity; and in the process disability is reproduced as a platform for interrogation and resistance. The disabled bodies thus, become both the site of oppression and space of doing ${ }^{18}$. Education in this context represents a mode of social control, where students not only learn to experience their bodies but the importance of controlling the disruptive excesses of the unruly bodies. This on the other hand, may account for the overarching emphasis on "remediation", "recovery", "discipline" and careful monitoring of the curriculum. Erevelles observes that the disabled body is rendered invisible to enable the social dominant class to preserve the illusions of autonomy, rationality and control ${ }^{19}$.

\footnotetext{
${ }^{16}$ Erevelles Ibid.

${ }^{17}$ Oliver, Michael. (1996). Understanding Disability: From Theory to Practice. New York: St. Martin's Press. Chapter 3. 30-42.

${ }^{18}$ Paterson and Hughes, 1999: p. 597.

${ }^{19}$ Erevelles 35.
} 


\section{Conclusion}

In this analysis, disability discourses have provided lenses through which to understand how disability is done in the bodies, and in everyday life within different socio-cultural backgrounds. It reveals how bodies are made to disappear and dys/appear when confronted with social normative constructs of the dominant class. Domba's transplanted kidney, as in the bodies of the segregated students remains both a site of oppressive subjectivity, a space of contradictions and negotiations at which we learn how bodies relate with the world, and following this relationship the bodies are changed, providing means for these bodies to speak back to the world. Domba's body was a space of intersection and paradox in which two "disabled bodies"- his corporeal reality, and the transmigrated kidney refused to transcend their embodied contradictions.

The Ontario Ministry of Education, Educational Psychologist, Medical Practitioners and teachers in the province's educational system promulgated and sustained the policies that established and upheld the criteria for measuring who belongs to the category of the "normal" and those who do not meet this classification, and therefore are the deviant "other". The introduction of homeroom intervention classes is not simply intended therefore, to remedy the "helpless" and cognitively impaire students, but could as well serve to keep them away from obstructing the processes of learning in the "normal" system. It becomes critical to see how dysfunction is represented, and presents itself as a diminution of quality of life in the case of Domba. Dan Brock in Anita Silvers suggests that at a deep level, medicine views bodily parts and organs, individual human bodies and people from a functional perspective ${ }^{20}$ in Domba's experience that the transplanted kidney was commodified as a commercial product which could be used to achieve the recovery of functional loss. There was therefore a biomedical transmigration of organ as prescribed by the practice that confined and conducted surgery on him; while Domba's father and in-law operationalized the shamanic transmigration of soul and spirit. As in the case of children diagnosed with learning disabilities in Ontario junior/middle school in which the Ontario Ministry of Education, Educational Psychologist, Medical Practitioners and teachers in the province's educational system partnered in promulgating and sustaining the policies that established and upheld the criteria for measuring who belongs to the category of the "normal" and those who do not meet this classification, the deviant "other"; the opposing two socio-cultural blocs in this social space collaborated in recovering Domba's functional loss.

The case of transplanted kidney, as well as the bodies of the segregated students enlisted to Room two zero two of an Ontario school both double as sites of oppressive subjectivity, spaces of contradictions and negotiations at which awareness of how bodies interacts with the world, and following this relationship the bodies get transformed and therefore empowered to speak back to the world. Embedded in this shift in the paradigm for rethinking disability is a cue for visu-

\footnotetext{
${ }^{20}$ Silvers, Anita, 1998, Ibid.
} 
alizing Domba's body and those of the students living with learning disabilities as sites of political and socio-cultural confrontation in which the belligerents aim to establish supremacy and dominance, and as a corporeal reality in which bodies and commodified body parts concurrently represent symbols of subjective hegemony of the dominant social class, and a stage for re-examination, concession and adjustment between the opposing social factions.

\section{Conflicts of Interest}

The author declares no conflicts of interest regarding the publication of this paper.

\section{References}

(2001). Operationalizing the New Definition of Learning Disabilities for Utilization within Ontario's Educational System. Ontario: Learning Disabilities Association of Ontario.

Clare, E. (2001). Stolen Bodies, Reclaimed Bodies: Disability and Queerness. Public Culture, 13, 359-365. https://doi.org/10.1215/08992363-13-3-359

Erevelles, N. (2000). Educating Unruly Bodies: Critical Pedagogy, Disability Studies, and the Politics of Schooling. Educational Theory, 50, 25-47. https://doi.org/10.1111/j.1741-5446.2000.00025.x

Ingstad, B., \& Whyte, S. R. (2007). Disability in Local and Global Worlds. Los Angeles, CA: University of California Press.

Julie, S. J. (2019). Rutgers Developmental Disabilities Lecture Series. Kristine Foss. Disability Solutions.

https://www.disabilitytalent.org/single-post/2018/07/19/Social-Constructs-of-Disability

Lott, B. (2017). Social Constructs of Disability. Disability Solutions. https://www.disabilitytalent.org/single-post/2018/07/19/Social-Constructs-of-Disability

Matthews, H. (2019). Senate Committee Corrects Some Weaknesses in Bill C-81, Disability Solutions.

http://www.ccdonline.ca/en/socialpolicy/fda/Media-Release-SOCI-4May2019

McMahon, B. (2002). Putting the Elephant into the Refrigerator. McGill Journal of Education, 38, 257-273.

Oliver, M. (1996). Understanding Disability: From Theory to Practice (Chapter 3, pp. 30-42). New York: St. Martin's Press. https://doi.org/10.1007/978-1-349-24269-6

Paterson, K., \& Hughes, B. (1999). Disability Studies and Phenomenology: The Carnal Politics of Everyday Life. Disability \& Society, 14, 597-610.

https://doi.org/10.1080/09687599925966

Silvers, A. (1998). A Fatal Attraction to Normalizing: Treating Disabilities as Deviation from "Species-Typical" Functioning. In P. Erik (Ed.), Enhancing Human Traits: Ethical and Social Implications. Washington DC: Georgetown University Press.

Solis, S. (2006). I'm "Coming Out" as Disabled, but I'm "Staying in" to Rest: Reflecting on Elected and Imposed Segregation. Equity and Excellence in Education, 39, 146-153.

https://doi.org/10.1080/10665680500534007 